\title{
Endoscopic hemostasis with multiple hemoclips and an endoloop for uncontrolled peptic ulcer bleeding
}

A method using a combination of multiple hemoclips and an endoloop was introduced for treating peptic ulcer bleeding and the large mucosal defects after endoscopic mucosal resection (EMR) or endoscopic submucosal dissection (ESD) [14]. We report the combined use of multiple hemoclips and an endoloop in patients with uncontrolled peptic ulcer bleeding. The endoscopic examination and therapy were performed using a one-channel endoscope. In contrast to a two-channel endoscope, a one-channel endoscope permits separating one catheter containing a clip from the other catheter containing an endoloop, and it also provides a wide range of therapeutic actions during combination therapy. The combination therapy was conducted using the step-bystep method ( $\bullet$ Figs. 1 and 2 ).

Before insertion of the endoscope into the patient, alligator forceps were inserted into the working channel of the endoscope. We slightly released the catheter equipped with an endoloop, and the alligator forceps caught the tip of the endoloop. Next, the alligator forceps were pulled back into the working channel as much as possible to prevent contact injury to the patient. We then grasped the tip of

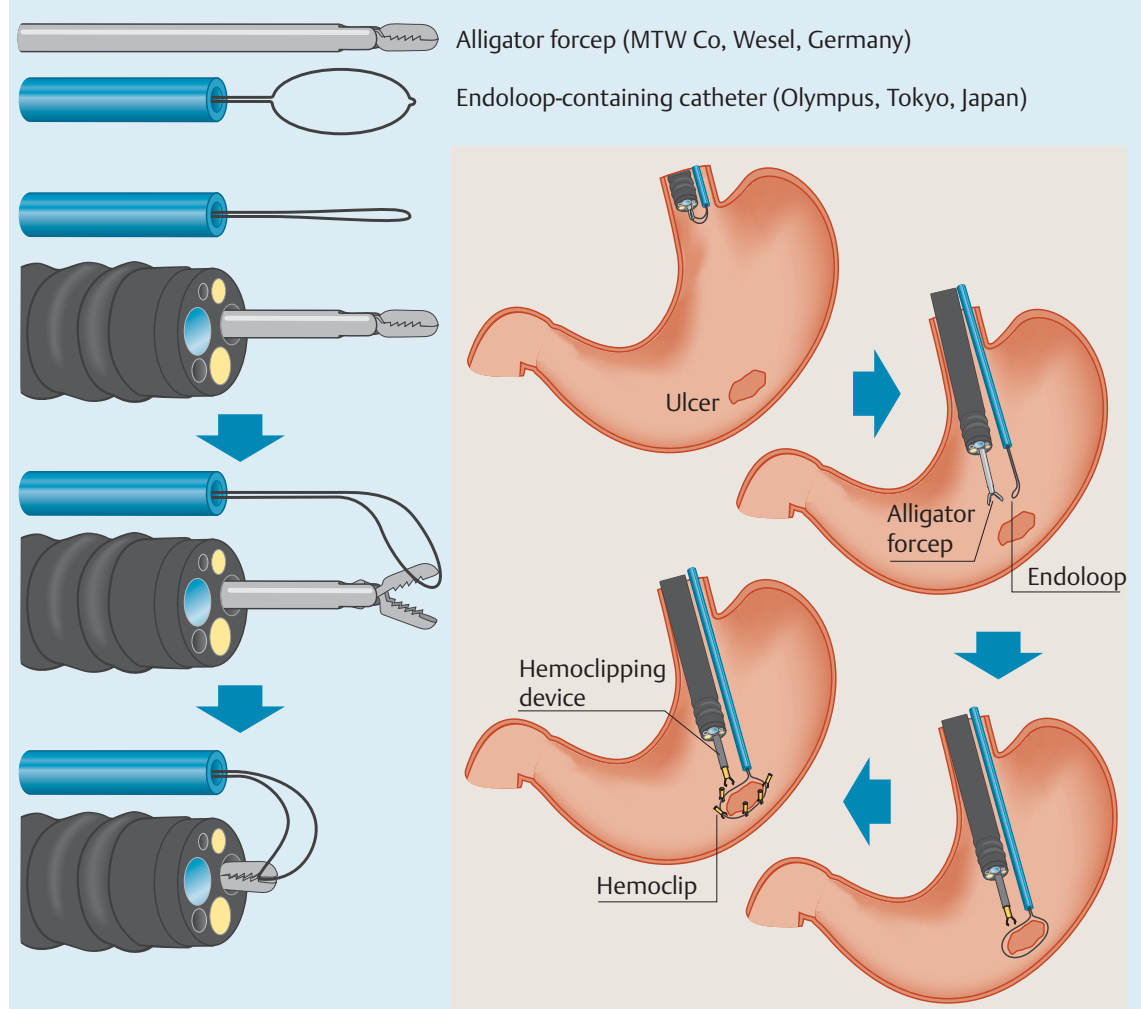

Fig. 1 Illustration of endoscopic hemostasis with a combination of multiple hemoclips and an endoloop.
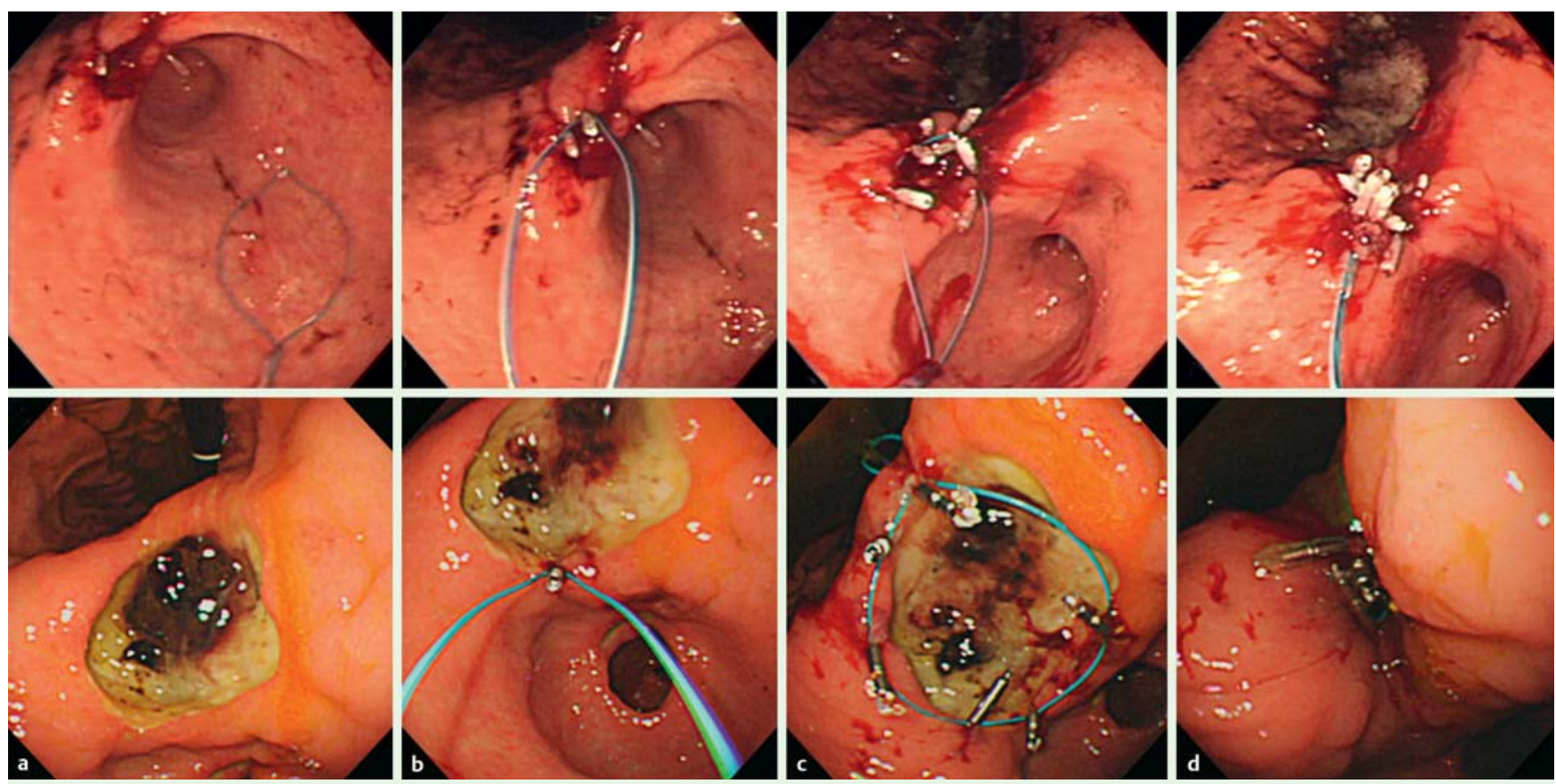

Fig. 2 Upper gastrointestinal endoscopic pictures of two patients. a Large, oozing ulcers at the angle of the stomach. $\mathbf{b}$ An endoloop and hemoclip were placed at the edge of the ulcer margin at the distal side. c The endoloop was attached at the ulcer margin and caught and fixed with multiple hemoclips. d Tightening of the endoloop closed the bleeding ulcer. 
the endoscope along with the tip of the endoloop containing the catheter, and we inserted all this into the patient. The endoscope and the catheter containing the endoloop were placed near the bleeding ulcer. The alligator forceps were opened for detaching the catheter with the endoloop. Then the endoloop was fully released and shaped. After insertion of the clipping catheter equipped with a hemoclip into the working channel, we caught the tip of the endoloop with the hemoclip and started attaching the clips from the distal margin; several hemoclips were sequentially attached with the endoloop around the margin of the ulcer. Finally, we tightened the endoloop and this closed the bleeding ulcer. The ulcer margins were almost perfectly joined and they covered the ulcer's base.

Endoscopy_UCTN_Code_TTT_1AO_2AD

Competing interests: None
D. H. Kim, C.-I. Kwon, J. G. Chung,

K. H. Ko, M. D. Kim, S. P. Hong,

P. W. Park

Digestive Disease Center, CHA Bundang Medical Center, CHA University, Seongnam, Korea

\section{References}

1 Rácz I, Kárász T, Saleh H. Endoscopic hemostasis of bleeding gastric ulcer with a combination of multiple hemoclips and endoloops. Gastrointest Endosc 2009; 69: $580-$ 583

2 Endo M, Inomata M, Terui T et al. New endoscopic technique to close large mucosal defects after endoscopic mucosal resection in patients with gastric mucosal tumors. Dig Endosc 2004; 16: 372-375

3 Matsuda T, Fujii T, Emura F et al. Complete closure of a large defect after EMR of a lateral spreading colorectal tumor when using a two channel colonoscope. Gastrointest Endosc 2004; 60: 836-838

4 Sanders MK, Malick J, Fasanella KE et al. Endoscopic closure of iatrogenic duodenal perforation during EUS in a patient with unusual anatomy. Gastrointest Endosc 2008; 68: $802-804$

\section{Bibliography}

Dol 10.1055/s-0030-1255986

Endoscopy 2011; 43: E3-E4

(c) Georg Thieme Verlag KG Stuttgart · New York · ISSN 0013-726X

\section{Corresponding author}

\section{C.-I. Kwon, MD, PhD}

Digestive Disease Center

CHA Bundang Medical Center

CHA University

351 Yatap-dong

Bundang-gu

Seongnam, 463-712

South Korea

Fax: +82-31-780-5219

endoscopy@cha.ac.kr 